\title{
Determining the chemical activity of hydrophobic organic compounds in soil using polymer coated vials Fredrik Reichenberg1,2, Foppe Smedes ${ }^{3}$, Jan-Åke Jönsson ${ }^{2}$ and Philipp Mayer*1
}

\author{
Address: ${ }^{1}$ Department of Environmental Chemistry and Microbiology, National Environmental Research Institute, University of Aarhus, PO Box \\ 358, 4000 Roskilde, Denmark, ${ }^{2}$ Division of Analytical Chemistry, Lund University, PO Box 124, S-221 00 Lund, Sweden and ${ }^{3}$ Ministry of \\ Transport, Public Works and Water management, National Institute for Costal and Marine Management/RIKZ, PO Box 207, 9750 AE Haren, \\ Netherlands \\ Email: Fredrik Reichenberg - fredrik.reichenberg@gmx.net; Foppe Smedes - foppe@fsmedes.nl; Jan- \\ Åke Jönsson - jan_ake.jonsson@analykem.lu.se; Philipp Mayer* - phm@dmu.dk \\ * Corresponding author
}

Published: 6 May 2008

Chemistry Central Journal 2008, 2:8 doi:10.1186/1752-153X-2-8

This article is available from: http://journal.chemistrycentral.com/content/2/I/8

(C) 2008 Reichenberg et al

This is an Open Access article distributed under the terms of the Creative Commons Attribution License (http://creativecommons.org/licenses/by/2.0), which permits unrestricted use, distribution, and reproduction in any medium, provided the original work is properly cited.
Received: 7 February 2008

Accepted: 6 May 2008

\begin{abstract}
Background: In soils contaminated by hydrophobic organic compounds, the concentrations are less indicative of potential exposure and distribution than are the associated chemical activities, fugacities and freely dissolved concentrations. The latter can be measured by diffusive sampling into thin layers of polymer, as in, for example, solid phase micro-extraction. Such measurements require equilibrium partitioning of analytes into the polymer while ensuring that the sample is not depleted. We introduce the validation of these requirements based on parallel sampling into polymer layers of different thicknesses.
\end{abstract}

Results: Equilibrium sampling devices were made by coating glass vials internally with 3-12 $\mu \mathrm{m}$ thick layers of polydimethylsiloxane (PDMS). These were filled with slurries of a polluted soil and gently agitated for 5 days. The concentrations of 7 polycyclic aromatic hydrocarbons (PAHs) in the PDMS were measured. Validation confirmed fulfilment of the equilibrium sampling requirements and high measurement precision. Finally, chemical activities of the PAHs in the soil were determined from their concentrations and activity coefficients in the PDMS.

Conclusion: PAHs' thermodynamic activities in a soil test material were determined via a method of uptake into PDMS. This can be used to assess chemical exposure and predict diffusion and partitioning processes.

\section{Background}

Chemical activity and the closely related fugacity were suggested as measures of chemical behaviour and affinity by G. N. Lewis in his now century old formulation of chemical thermodynamics [1]. Since then they have been used to understand, predict and describe physico-chemical phenomena such as osmosis [2], mineral stability [3] and cholesterol biosynthesis $[4,5]$. That the chemical activity of a hydrophobic organic soil pollutant is important for its bioavailability has recently been proposed [6]. One reason for this is that partitioning occurs spontaneously down gradients in chemical activity. Equilibrium partitioning is defined by equal chemical activities, forming the basis for equilibrium partitioning theory [7] and 
related models (e.g. $[8,9])$. All of which is taken to contend that the mentioned thermodynamic quantities can help in the prediction of chemical bioaccumulation and toxicity [10]. Despite this promising perspective we found few published methods to determine the chemical activity $[11,12]$ or fugacity [13-15] of hydrophobic organic pollutants in environmental samples.

In some instances chemical activities can be measured with equilibrium sampling techniques. One prominent approach, Solid Phase Micro-Extraction (SPME), was introduced in 1990 by Arthur and Pawliszyn [16]. The SPME format is very attractive as an Equilibrium Sampling Device (ESD) because the sampling phase is a small volume $(\mu \mathrm{L})$ of polymer with a relatively large surface area [17]. The micro-extraction is caused by molecular diffusion across that surface, which is driven by the chemical activity of the analyte in the sample and results in a measurable concentration in the polymer. Diffusive sampling into thin layers of polymer is suitable for measurement of chemical activity and fugacity if certain conditions are fulfilled [17]. First, equilibrium (i.e. equal chemical activity) between the sample and polymer must be reached. Second, the uptake into the polymer must not deplete the sample of analyte, as this would reduce the chemical activity in the sample [18]. Third, polymer surface adsorption must be negligible because fugacity and activity is only proportional to the absorbed (dissolved) concentration within the polymer [19]. This proportionality links an observable, physically real concentration, to the abstract but meaningful thermodynamic activity function. The chemical activity $(a)$ is thus given by:

$$
a=\gamma_{\mathrm{P}} \cdot C_{\mathrm{P}}
$$

where $\gamma$ denotes the activity coefficient and $C$ the concentration of the analyte in the polymer ( subscript $_{\mathrm{P}}$ ). At equilibrium, the analyte concentration in the polymer reveals new and important information about the sample.

Clearly, when compared to the more traditional analytical extraction techniques, equilibrium sampling differs in both means and ends. Not surprisingly they also present other challenges, and method performance must be evaluated differently. For example, Soxhlet extractions used in quantitative analytical methods are designed for complete analyte recovery, and tend to be sample destructive yielding "dirty" extracts that require further work-up before analysis. For such exhaustive extractions, it is well established that analyte recovery during extraction and cleanup can be validated by internal standards. Equilibrium sampling, in contrast, dictates that the sample must remain intact during the procedure. For example, grinding [20], heating and soaking soil samples in organic solvents are to be avoided as far as they destroy the matrix and might alter the chemical activity to be measured. Likewise, it must be assured that the ESD polymer is not damaged by abrasion, or its surface fouled by soil particles during the agitated equilibration procedure. These special criteria for valid equilibrium sampling are known, but inadequately addressed in practice.

Equilibrium sampling has some unusual criteria, and reliability could be gained from an integrated validation of (1st) equilibrium, (2nd) negligible depletion of sample and (3rd) negligible impact of other experimental artefacts such as adsorption on the polymer surface. This is especially important when long equilibration times (days) make separate validation experiments costly or the polymer phase is given a large surface area to volume (A/ $\mathrm{V})$ ratio to speed up equilibration. However, we could not find any published equilibrium sampling methods able to fulfil these validation requirements.

Diffusive samplers with multiple A/V ratios can be used to confirm equilibrium without time series measurements $[17,21]$. Mechanistic arguments show that the $\mathrm{A} / \mathrm{V}$ approach allows not only validation of equilibrium, but extends to disclosing other potential artefacts such as sample depletion and polymer surface adsorption. The subsequent discussion explains the benefits of equilibrium sampling with devices of multiple coating thicknesses.

Consider the case of parallel sampling with several ESDs having different polymer volumes $\left(\mathrm{V}_{\mathrm{p}}\right)$ but similar effective surface areas. In the kinetic uptake regime, the amount of analyte $\left(n_{a}\right)$ in the polymer results from a diffusive mass transfer proportional to the surface area, but independent of the polymer volume (Figure 1A). In the intermediate uptake regime, back-diffusion out of the polymer becomes increasingly significant, and $\mathrm{n}_{\mathrm{a}}$ depends then on both the surface area and $V_{p}$ (Figure 1B). At equilibrium, $n_{a}$ is proportional to $V_{p}$ (Figure $1 C$ ), which allows the confirmation of equilibrium without studying up-take kinetics while also providing the measurements needed for the calculation of mean concentration and standard deviation. This economises time and analytical resources by allowing the same data both to confirm and measure equilibrium conditions.

Equilibrium sampling with multiple polymer coating thicknesses can also reveal various sampling artefacts such as surface adsorption, polymer abrasion and sample depletion. Proportionality between $n_{a}$ and $V_{p}$ confirms valid sampling (dashed line, Figure 2). Surface adsorption would contribute an extra amount to $\mathrm{n}_{\mathrm{a}}$ independently of the polymer volume and to a positive bias on the intercept (Figure 2A). Abrasive loss of polymer, that in our experience predominantly befall thin layers, would lead to a reduced $n_{a}$ compared to the artefact free situation (Figure 

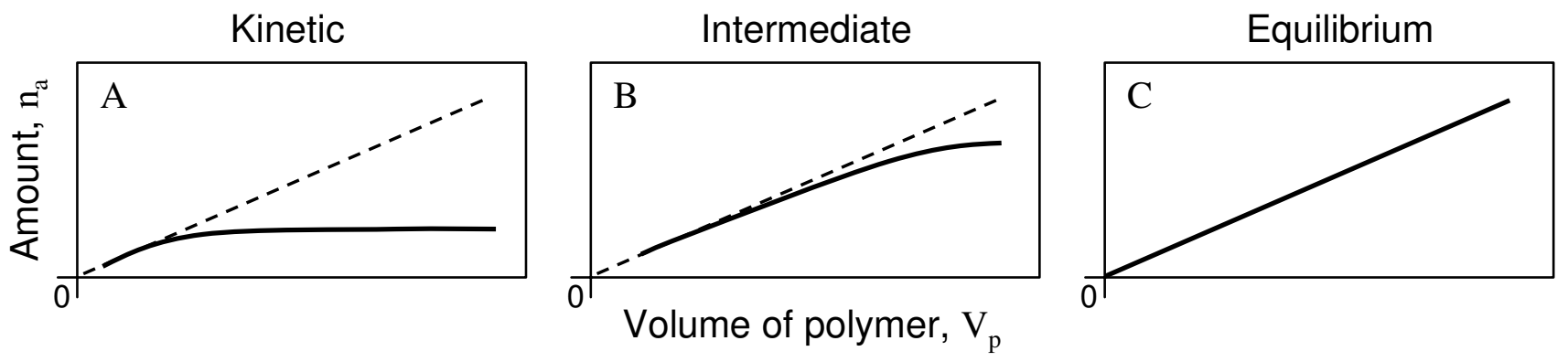

Figure I

Schematic representation of the amount of analyte $\left(n_{a}\right)$ in thin layer ESDs as a function of their polymer volume $\left(V_{p}\right)$ at two time points before and at equilibrium. Dashed line represents equilibrium conditions.

2B). Sample depletion, meaning a significant impact from analyte mass-transfer during equilibration, would lead to a reduction of the analyte concentration with increasing $\mathrm{V}_{\mathrm{P}}$ and to curving in Figure 2C. Other and more complicated situations can easily be imagined. However, if the measured amounts, when plotted as in Figure 2, can be connected by a straight line passing through the origin, this is a strong indication of a successful and valid equilibrium sampling.

Many different ESD formats have been applied, including PDMS coated glass fibres [22], low-density polyethylene strips [23,24], polyoxymethylene strips [25], poly(ethylene-vinyl acetate) films [14] and liquid-filled, hollowfibre membranes [26], each with their specific operational window. Other alternatives include the Twister ${ }^{\circledast}$ (sorptive stir-bar) and the Immobilised Liquid Extraction ${ }^{\mathrm{TM}}$ Caps. Very recently Minhas et al. published work on vials internally coated with poly(ethylene-vinyl acetate) [27]. This integration of glass container with the sampling phase allows soil and sediment samples to be transported and stored, for example, while equilibrating with the polymer coating. All the while minimising sample handling, increasing work efficiency and reducing worker exposure.
The limitations of existing ESDs and theoretical arguments suggest that equilibrium sampling with multiple coating thicknesses integrated within a sample container can provide validated and simplified measurements of chemical activity, fugacity and freely dissolved concentration. The aim of this paper is therefore to present ESDs consisting of $\mu \mathrm{m}$-thick PDMS coatings of multiple thicknesses and their application to the measurement of chemical activity of PAHs in soil.

\section{Working principle}

The ESDs consist of PDMS layers deposited on the internal wall of sample glass vials. The ESDs are equivalent in all respects apart from the thickness of the PDMS. This in vial-sample preparation minimises sample handling, and parallel application of the different thicknesses allows validation of the equilibrium sampling to measure chemical activity. The procedure consists of three parts:

1. Vials with 3-12 $\mu \mathrm{m}$ thin layers of PDMS are equilibrated with samples of the investigated soil.

2. Solvent extracts of the PDMS are analysed for the content of PAHs to determine $C_{\text {PDMs }}$.


Figure 2

Schematic representation of the amount of analyte $\left(n_{a}\right)$ in/on thin layer ESDs as a function of their polymer volume $\left(V_{p}\right)$ in three cases of equilibrium sampling artefact. Dashed line represents artefact-free conditions. 
Table 2: Method Limits of Quantification (LoQ)

\begin{tabular}{lcccc}
\hline \multicolumn{5}{c}{ LoQ } \\
\hline Compound & $\boldsymbol{C}_{\text {MeOH }}$ & $C_{\text {PDMS }}$ & $\boldsymbol{a}_{\text {soil }}$ & Depletion of sample \\
\hline & $\mathbf{n M}$ & $\mu \mathrm{M}$ & $10^{-6}$ & $\%$ \\
\hline Nap & 19.5 & 2.5 & 2.6 & \\
Ace & 4.1 & 0.5 & 1.5 & 0.26 \\
Flo & 11.6 & 1.5 & 3.2 & \\
Phe & 6.0 & 0.8 & 3.1 & \\
Ant & 1.8 & 0.2 & 1.3 & 0.01 \\
Flu & 12.4 & 1.6 & 11.2 & 0.01 \\
Pyr & 6.5 & 0.8 & 3.1 & \\
BaA & 2.7 & 0.3 & 5.3 & 0.01 \\
Chr & 6.3 & 0.8 & 21.6 & \\
BkF & 0.7 & 0.1 & 2.9 & 0.01 \\
BaP & 0.8 & 0.1 & 2.8 & 0.02 \\
Ind & 12.9 & 1.6 & 137 & 0.02 \\
& & & & \\
\hline
\end{tabular}

3. The chemical activity is found as the product of $C_{\text {PDMS }}$ and an activity coefficient (Equation 1).

\section{Results and discussion}

Determining equilibrium partitioning concentrations in PDMS coatings

After sampling the soil in PDMS coated vials, the quantities of PAHs $\left(\mathrm{n}_{\mathrm{PAH}}\right)$ in the PDMS were extracted to methanol, measured by HPLC, and plotted against the PDMS volumes (Figure 3 ). Linear regressions (least square fit, forced $[0 ; 0]$ ) with $\mathrm{r}^{2}$ exceeding 0.90 were obtained for 7 PAHs. The graphs clearly demonstrate that $\mathrm{n}_{\mathrm{PAH}}$ is proportional to $V_{\text {PDMS }}$, which is consistent with artefact-free equilibrium sampling.

Equilibrium partitioning concentrations in the PDMS $\left(C_{\mathrm{PDMS}}\right.$, Table 1$)$ were calculated as the arithmetic mean of
Table I: Measured equilibrium partitioning concentration in PDMS ( $\left.C_{\text {PDMS }}\right)$, chemical activity $(a)$ and concentration $\left(C_{\text {soil }}\right)$ of seven PAHs in the test soil

\begin{tabular}{|c|c|c|c|c|}
\hline \multirow[t]{2}{*}{ Compound } & \multicolumn{2}{|c|}{$C_{\text {PDMS }}( \pm \mathrm{SD})^{a}$} & \multirow{2}{*}{$\begin{array}{l}a_{\text {soil }} \\
10^{-6}\end{array}$} & \multirow{2}{*}{$\begin{array}{c}\mathrm{C}_{\text {soil }} \\
\mathrm{mg} / \mathrm{kg}^{b}\end{array}$} \\
\hline & & & & \\
\hline Ace & 4.42 & $( \pm 0.17)$ & 13 & I \\
\hline Ant & 1.51 & $( \pm 0.05)$ & 8.6 & 5 \\
\hline Flu & 2.55 & $( \pm 0.10)$ & 18 & 17 \\
\hline $\mathrm{BaA}$ & 1.50 & $( \pm 0.04)$ & 23 & 10 \\
\hline $\mathrm{BkF}$ & 1.07 & $( \pm 0.03)$ & 35 & 8 \\
\hline $\mathrm{BaP}$ & 2.23 & $( \pm 0.04)$ & 62 & 9 \\
\hline Ind & 1.81 & $( \pm 0.07)$ & $|5|$ & 7 \\
\hline \multicolumn{5}{|l|}{$a_{n}=9-8$} \\
\hline b dry matter & & & & \\
\hline
\end{tabular}

the 9 coated vials. The relative standard error of the arithmetic mean ranged from 2 to $4 \%$, a very high precision. Additionally, $C_{\mathrm{PDMS}}$ was also determined as the slope of the linear regression. These slope estimates and the arithmetic means hardly differed (2-4\%), and both calculation principles are equally suitable. A high accuracy in the $C_{\mathrm{PDMS}}$ measurements is expected, since the potential for systematic errors associated with the input parameters $\left(\mathrm{n}_{\mathrm{PAH}}, \mathrm{V}_{\mathrm{MeOH}}, \mathrm{V}_{\mathrm{PDMS}}\right)$ are limited.

The method limit of quantification (LoQ) was defined as 10 times the standard deviation of the signal noise level. In terms of $C_{\mathrm{PDMS}}$, LoQ ranged from 0.1 to $2.5 \mu \mathrm{M}$ (Table 2 ), and varied with the PAHs' specific fluorescence quantum yield at the detector settings of the HPLC. There are several ways to lower the detection limits, including evaporative concentration of the methanol extract and the use of more sensitive detectors. If analytical procedures require, the vials may be extracted with other solvents
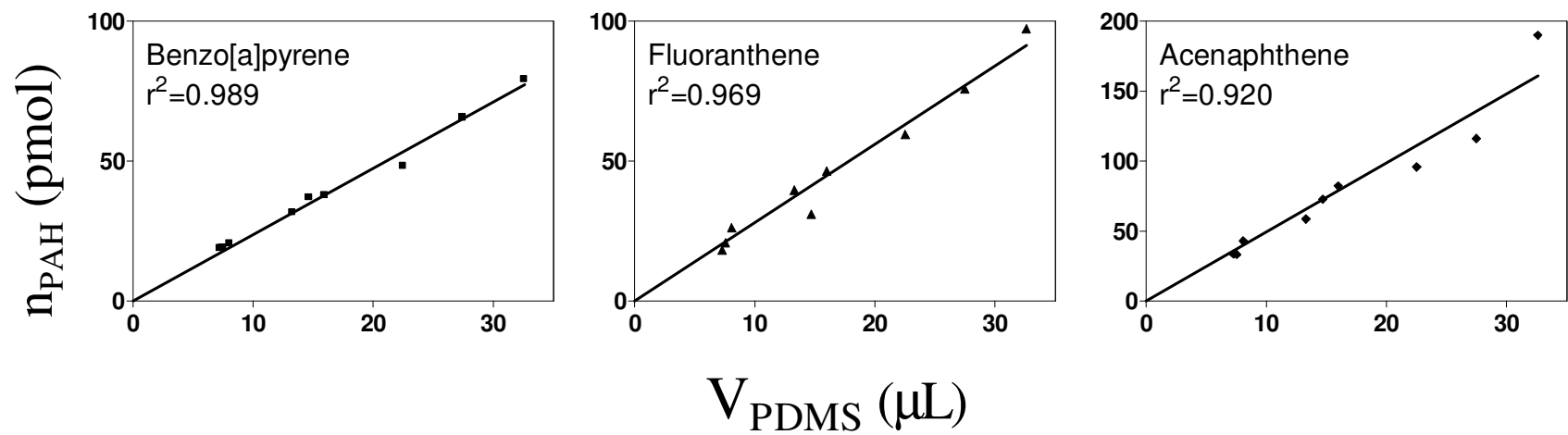

Figure 3

Amounts of analyte PAH ( $\mathrm{n}_{\mathrm{PAH}}$ ) plotted as a function of volume of PDMS ( $\left.\mathrm{V}_{\mathrm{PDMS}}\right)$ in nine coated vials after equilibration with the test soil (in slurry) for five days. Three representative compounds were selected for having the highest, median and lowest $r^{2}$-values. 
than methanol (e.g. pentane). This may require a more rigorous pre-extraction of siloxane oligomers from the coatings to keep these from co-extracting with the analytes [28].

Values of $C_{\mathrm{PDMS}}$ can be applied in many different ways without any further conversion. Gradients in $C_{\text {PDMS }}$ follow the potential for diffusion and measured values should fall in the direction of passive transport gradients within or between environmental compartments. For example, as predictor of PCB bioaccumulation into worms, $C_{\mathrm{PDMS}}$ is directly comparable between both dissimilar sediments [29] and soils [30]. Likewise, $C_{\mathrm{PDMS}}$ can be used to monitor environmental processes in time, such as the effect of aging or the (bio)degradation of PAHs in soil. A decrease in $C_{\mathrm{PDMS}}$ is sufficient to show a decrease in chemical activity.

\section{Determining freely dissolved concentration and chemical activity}

$C_{\text {PDMS }}$ is proportional to the freely dissolved concentration $\left(C_{\text {free }}\right)$, chemical activity and also fugacity [6]. $C_{\text {free }}$ can be determined with the analyte specific PDMS-water partition ratio $K_{\mathrm{PDMS} / \mathrm{aq}}$ :

$$
C_{\text {free }}=\frac{C_{\text {PDMS }}}{K_{\text {PDMS } / \mathrm{aq}}}
$$

This calibration towards $C_{\text {free }}$ has already been covered in several publications (e.g. [17,22,31,32]), and the present paper focuses on the determination of chemical activities from $C_{\mathrm{PDMS}}$ (Equation 1).

\section{Activity coefficients in PDMS}

The activity coefficients in Table 3 were determined at solubility (Equation 3). At this limit, the chemical activity of the solute PAH in the saturated solvent is usually equal to the activity of the PAH in its pure solid crystal state, $a_{\mathrm{xstal}}$. In turn, $a_{\mathrm{xstal}}$ is exponentially related to the free energy difference between the compound's liquid and solid states at the given temperature. This difference can be determined from the melting point temperature, heat of fusion and heat capacity as detailed elsewhere $[33,34]$. However, $a_{\text {xstal }}$ were instead estimated through Equation 4, for reasons of consistency. For similar reasons, the activity coefficients were based on solubility in methanol and the partition ratio to the PDMS. First, $\mathrm{S}_{(\mathrm{s}) \mathrm{MeOH}}$ and $\mathrm{K}_{\mathrm{PDMS} / \mathrm{MeOH}}$ could be determined with sufficient precision (Table 3 and Table A in Additional File 1). Second, $\mathrm{S}_{(\mathrm{s}) \mathrm{MeOH}}$ for several PAHs are published and can be used to validate experimental accuracy (Figure A in Additional File 1). Third, the use of partitioning solutions and solubilities in the calibration of ESDs is consistent with current practice $[5,11,15,17,22,35]$ and carries certain advantages.

The practice of ESD calibration via methanol partitioning standards may prove valuable in the future. Already now, methods to conduct multi-compartment studies including equilibrium sampling measurements are available $[14,22,23,36]$. However, these methods use different polymers and this may confound a comparison of results. For

Table 3: Melting points $\left(T_{m}\right)$, crystal activities $\left(a_{x s t a l}\right)$, solubilities $\left(S_{(s) M e O H}\right)$ and activity coefficients $\left(\gamma_{\text {MeOH }}\right)$ in methanol. MethanolPDMSe partition ratios $\left(K_{\mathrm{PDMS} / \mathrm{MeOH}}\right)$ and activity coefficients $\left(\gamma_{\mathrm{PDMS}}\right)$ in the PDMS for 12 PAHs

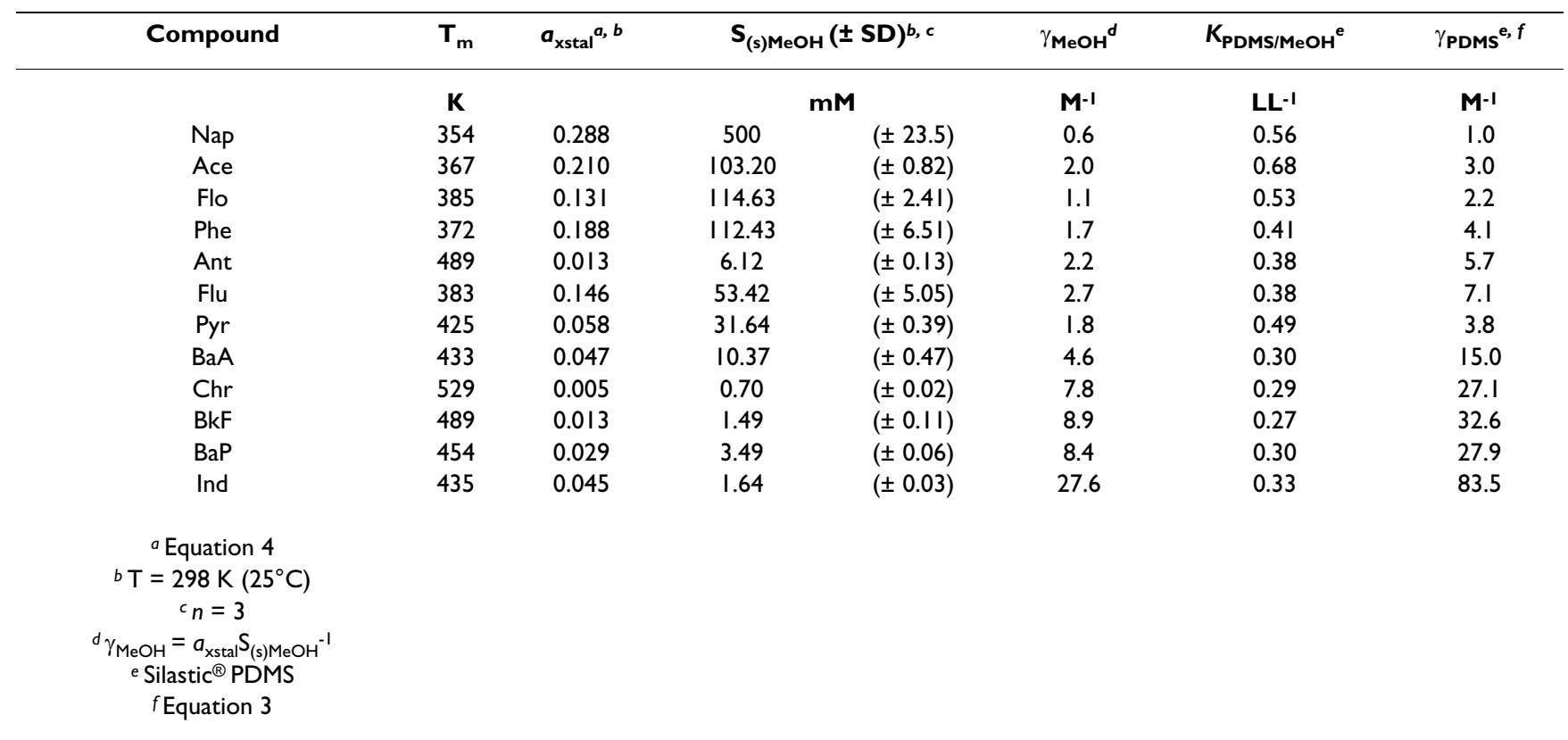


example, the inter-calibration of two commercial PDMS formulations, Silastic ${ }^{\circledast}$ and SSP-M823, revealed an almost $40 \%$ difference in their partitioning properties (Table $\mathrm{A}$ in Additional File 1). This kind of information is important for comparing measurements from different ESDs.

\section{Equilibrium sampling devices with multiple $\mathbf{A} / \mathbf{V}$ ratios}

The in vial-ESD format and $\mathrm{A} / \mathrm{V}$-approach has unique and important features. Most important is the integrated QA/ QC of the measurements. This extends the applicability towards very difficult or very dirty samples that might cause problems during equilibration or analysis due to their composition. Examples of troublesome sample components include soot particles with a high PAH content [25] and (micro)droplets of non-aqueous phase liquids (NAPLs) that may foul the PDMS surface. But, when using the in vial-ESD format, equilibrium sampling flaws can be inspected by plotting $\mathrm{n}_{\mathrm{a}}$ against $\mathrm{V}_{\text {PDMS }}$. This integrated validation makes the method reliable at its applicability limit, whereas other equilibrium sampling methods require a greater margin of safety. Second, the integration of thin polymer layers within sample vials [27] reduces the risk of measurement error. Handling procedures are minimised as sample material can be secured, transported, stored and equilibrated, under seal and in a single container. The subsequent liquid extract of the PDMS makes the method compatible with many standard analytical procedures. For example, addition of internal standards, clean-up and/or pre-concentration steps can be included in future equilibrium sampling method developments. The in vial-ESDs are both practical and versatile. Third, the design of the devices is also adaptable. The ESD dimensions can be tuned towards faster equilibration by reducing the polymer coating thickness [27]. Alternatively, detection limits can be lowered by increasing the $\mathrm{V}_{\mathrm{PDMS}}$ to sample a greater amount of analyte for detection. All of these advantages make ESDs with multiple $\mathrm{A} / \mathrm{V}$ ratios attractive.

\section{Experimental}

\section{In vial-ESD preparation}

3-12 $\mu \mathrm{m}$ layers of PDMS were prepared in $20 \mathrm{~mL}$ glass vials by dispersion coating in the following manner. The appropriate mass of medical adhesive, Silastic $\mathrm{C}^{\circledast}$ PDMS Silicone Type A (Dow Corning, Seneffe, BE; density $1.15 \mathrm{~kg} /$ $\mathrm{L}$ [28]) paste was dispersed in 10 times its volume in $\mathrm{n}$ pentane by wrist shaking and sonication. The dispersion was filtered (glass fiber, $0.7 \mu \mathrm{m}$ nominal, Pall Corp., MI) and diluted in a geometric series. All polymer dispersions were used at the day of preparation and should be prepared using disposable glassware and materials to avoid inadvertent formation of insoluble polymer layers.

After careful tare on an analytical balance (Sartorius BP $210 \mathrm{~S}, \mathrm{~d}=0.1 \mathrm{mg}$ ), the vials to be coated were placed hor- izontally on a roller-mixer (Stuart sci., Stone, UK). While rotated (33 rpm) $3.0 \mathrm{~mL}$ of the appropriate dispersion was added to each vial. The solvent was evaporated under a gentle stream of nitrogen and the vials were left to polymerise for $72 \mathrm{~h}$ in a fume hood. Siloxane oligomers were removed from the cross-linked PDMS by three extractions with ethyl acetate ( $3 \mathrm{~mL}, 10 \mathrm{~min}$ vigorous shaking). The vials were again balanced to determine the mass of PDMS now covering their inner sidewall surface.

\section{Equilibrium sampling procedure}

PDMS-coated vials with different coating thicknesses were filled with $18-20 \mathrm{~g}$ of the test soil $(n=9) .10 \mathrm{~mL}$ aqueous solution of sodium azide $(0.5 \mathrm{~g} / \mathrm{L})$ was added to each vial to inhibit microbial activity and to create a soil suspension for the sampling. Vials were capped with metal lined screw caps and placed horizontally in a customised holder rotated $(6 \mathrm{rpm})$ on a roller-mixer for $122 \mathrm{~h}$.

\section{PDMS coating extraction}

Soil content was removed, the vials were rinsed with a little distilled water on a whirly mixer before being wiped internally with lint-free tissue. To each vial was then added $1.00 \mathrm{~mL}$ methanol. The vials were again capped and rotated for $12 \mathrm{~h}$. The methanol extracts were collected and stored in freezer $\left(-20^{\circ} \mathrm{C}\right)$ until analysed for PAHs.

\section{Extract analysis}

Methanol extracts of PDMS were analysed for PAHs by HPLC-fluorescence detection (Agilent 1100 system with G1321A FLD (Ex. 260 nm; Em. 350, 420, 440 and 500 $\mathrm{nm}$ ). Separation column: CP-Ecospher $4 \mathrm{PAH}$ (Varian Inc., Palo Alto, CA) operated at $0.5 \mathrm{ml} / \mathrm{min}\left(28^{\circ} \mathrm{C}, 10 \mu \mathrm{L}\right.$ injection); Mobile phase: methanol, SUPER-Q treated water (Millipore, MA); Gradient (in \%methanol, by weight): $\mathrm{t}=0 \mathrm{~min} 80 \% ; \mathrm{t}=5-30 \mathrm{~min}$ linear gradient $80-$ $100 \% ; \mathrm{t}=30-45 \min 100 \%$. Quantification was accomplished by a five-point external standard curve. Extract analysis was carried out within 2 weeks after sampling.

\section{Solubilities in methanol}

Solubilities were measured by placing excess PAH crystals together with methanol in PTFE-sealed glass vials and equilibrating these in a thermostated water bath at $25.0 \pm$ $0.1^{\circ} \mathrm{C}$ for at least 3 days. Attainment of the solubility limit was verified by repetitive measurements on consecutive days. Aliquots of the saturated methanol solutions were passed through $0.2 \mu \mathrm{m}$ PTFE-filters into volumetric flasks and quantitatively diluted with methanol to reach suitable concentrations before analysis by the HPLC-FLD method described above.

\section{PDMS-methanol partition ratios}

Partition ratios $\left(K_{\mathrm{PDMS} / \mathrm{MeOH}}\right)$ between Silastic ${ }^{\circledR} \mathrm{PDMS}$ polymer and methanol was measured in a separate experi- 
ment. First, PDMS sheets were prepared by filling a polyethylene mold $(0.25 \mathrm{~mm}$ high $)$ with Silastic ${ }^{\circledast}$ paste. The top surface was pressed even, and covered with wet tissue and a glass plate. After one week, the cross-linked PDMS was cut into sheets weighing approximately $1 \mathrm{~g}$, Soxhlet extracted (ethyl acetate, $100 \mathrm{~h}$ ) and then washed with methanol. A clean sheet and an excess of methanol solution containing all the analyte PAHs (approx. $25 \mu \mathrm{g} /$ L) were placed in a sealed amber glass container. After equilibration by shaking for $>1$ week at $20^{\circ} \mathrm{C}$, the methanol and PDMS were separately taken for extraction and analysis of the PAH contents by GC-MS as described in [37]. The respective, volume based, concentrations in the Silastic ${ }^{\circledast D}$ PDS sheet and the methanol solution were divided to calculate the partition ratios.

\section{Conclusion}

This study concludes that vials containing thin layers of PDMS can be used as equilibrium sampling devices. The methodology of parallel sampling in devices with different thickness PDMS layers has unique and important features. Most important is an integrated QA/QC of the procedure. When conducted on a soil test material, results were confirmed as precise and valid measurements of equilibrium partitioning concentrations, $C_{\mathrm{PDMS}}$. These were then, by way of a separate calibration experiment, expressed as chemical activities of individual PAHs in the soil.

\section{Relevance for chemical risk assessment}

A risk assessment of the pollution in the test material soil is warranted by the present soil quality criterion for PAHs in Denmark. The legislation dictates that the sum of fluoranthene, benzo [a]pyrene, benzo [k]fluoranthene, and indeno [1,2,3-cd]pyrene may not exceed $4 \mathrm{mg} / \mathrm{kg}$ dry soil [38].

Several concerns regarding the risk posed by the PAHs in the polluted soil can be assessed with the chemical activities reported in Table 1. First, $a_{\text {soil }}$ quantifies the chemical pollutant's potential for partitioning and distribution to other materials in contact with the soil. This makes the activity relevant because it is first after release and transfer to a susceptible target that a PAH may cause detriment of health or effects on the environment. Second, $a_{\text {soil }}$ provides a measure for comparison of chemical contamination levels. The activity reflects a chemical's affinity (e.g. partial molar free energy of sorption) to the soil material. Soils are dynamic, heterogeneous and unpredictable geosorbents. Therefore, $C_{\text {soil }}$ is harder to interpret and compare than are concentrations in a well-defined, stable and homogenous phase such as PDMS. In consequence, equilibrium sampling measurements are useful because the results can easily be compared to the levels in other measured soils, in air, water or biological tissue, as well as to effect levels determined in toxicity studies, whenever such are available.

For example, comparison of different exposure routes may be part of health risk assessments. Cases may include, for instance, risk of systemic up-take after ingestion of polluted soil and inhalation of urban air. To illustrate, Figure 4 depicts chemical activities of several priority pollutant PAHs, both in the tested soil and in the gas phase of an urban atmosphere [39](Additional File 1). Comparatively, PAHs in the air seem to have greater chemical potential for diffusion through biological membranes, such as gastrointestinal or alveolar epithelium.

\section{Methods \\ Standards}

PAHs of $\geq 98 \%$ purity were obtained from Sigma-Aldrich (Copenhagen, DK) or Cambridge Isotope Lab. (Andover, MA).

\section{Solvents and chemicals}

P.a. grade n-pentane, ethyl acetate, sodium azide and HPLC-grade methanol were obtained from Merck (Darmstadt, DE).

\section{Soil material}

The PAH contaminated soil were excavated from a former manufactured gas plant site (Gaswerk Tiefstark, Klosterwall 2, Freie Hansestadt Hamburg, DE) and then compost treated by A/S Bioteknisk Jordrens (Esbjerg, DK) prior to this study. It contained $14 \%$ water, 5-7 \% organic carbon, $11-16 \%$ silt, 3-4\% clay and weathered coal-tar, petroleum residues, soot and ash.



\section{Figure 4}

Chemical activities in the test soil $(\diamond)$ compared to activities in the gas phase of Heraklion (GR) inner city air ( $\square$ ). The latter are based (see Additional File I) on gas phase concentrations, measured by high-volume sampling and reported in [39]. 
Table 4: List of abbreviations

\begin{tabular}{|c|c|c|}
\hline & & InChI \\
\hline Nap & Naphthalene & $\operatorname{lnChI}=\mathrm{I} / \mathrm{ClOH} 4 \mathrm{Cl} / \mathrm{cl} \mid \mathrm{l}-7-5-3-\mathrm{I}-2-4-6(5) 8(\mathrm{I}) \mathrm{I0}(\mathrm{I}) 9(7) \mathrm{I} / \mathrm{h} \mathrm{I}-4 \mathrm{H}$ \\
\hline Ace & Acenaphthene & $\mathrm{InChI}=\mathrm{I} / \mathrm{Cl} 2 \mathrm{HI} / \mathrm{cl}-3-9-4-2-6-\mathrm{II}-8-7-10(5-1) \mathrm{I} 2(9) \mathrm{I} / \mathrm{hl}-6 \mathrm{H}, 7-8 \mathrm{H} 2$ \\
\hline Flo & Fluorene & $\mathrm{InChl}=\mathrm{I} / \mathrm{Cl} 3 \mathrm{HI} / 0 / \mathrm{Cl}-3-7-12-10(5-\mathrm{I}) 9-\mathrm{II}-6-2-4-8-13(\mathrm{II}) \mathrm{I} / \mathrm{hl}-8 \mathrm{H}, 9 \mathrm{H} 2$ \\
\hline Phe & Phenanthrene & $\mathrm{InChl}=\mathrm{I} / \mathrm{Cl} 4 \mathrm{HI} / 0 / \mathrm{cl}-3-7-13-1|(5-1) 9-10-12-6-2-4-8-14(\mid 2)| 3 / \mathrm{hl}-10 \mathrm{H}$ \\
\hline Ant & Anthracene & $\mathrm{InChl}=\mathrm{I} / \mathrm{Cl} 4 \mathrm{HI} / \mathrm{cl}-2-6-12-10-14-8-4-3-7-13(14) 9-\mathrm{I}|(\mid 2) 5-\mathrm{I} / \mathrm{h}|-10 \mathrm{H}$ \\
\hline Flu & Fluoranthene & $\mathrm{InChl}=\mathrm{I} / \mathrm{Cl} 6 \mathrm{HIO} / \mathrm{cl}-2-8-13-12(7-1)|4-9-3-5-1 \mathrm{I}-6-4-10-15(\mid 3)| 6(\mid \mathrm{I}) \mid 4 / \mathrm{hl}-\mathrm{IOH}$ \\
\hline Pyr & Pyrene & $\mathrm{InChl}=1 / \mathrm{Cl} 6 \mathrm{HIO} / \mathrm{cl}-3-||-7-9-13-5-2-6-14-10-8-12(4-1)|5(\mid \mathrm{I})| 6(\mid 3) \mid 4 / \mathrm{hl}-10 \mathrm{H}$ \\
\hline $\mathrm{BaA}$ & Benzo [a]anthracene & 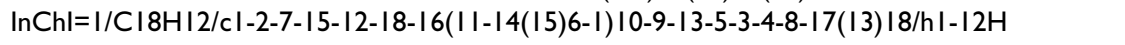 \\
\hline $\mathrm{Chr}$ & Chrysene & $\mathrm{InChI}=\mathrm{I} / \mathrm{Cl} 8 \mathrm{HI} / \mathrm{cl}-3-7-15-13(5-\mathrm{I}) 9-1 \mathrm{I}-18-16-8-4-2-6-14(16) 10-12-17(15) \mid 8 / \mathrm{hI}-12 \mathrm{H}$ \\
\hline $\mathrm{BkF}$ & Benzo $[k]$ fluoranthene & $\mathrm{InChl}=\mathrm{I} / \mathrm{C} 2 \mathrm{OHI} / \mathrm{cl}-2-6-15-12-19-17-10-4-8-13-7-3-9-16(20(13) \mid 7)|8(\mid 9)||-| 4(\mid 5) 5-\mathrm{I} / \mathrm{h}|-| 2 \mathrm{H}$ \\
\hline $\mathrm{BaP}$ & Benzo [a]pyrene & $\mathrm{InChl}=\mathrm{I} / \mathrm{C} 2 \mathrm{OHI} / \mathrm{cl}-2-7-17-\mathrm{I}(4-\mathrm{I})|2-16-9-8-13-5-3-6-14-10-\mathrm{II}-18(17) 20(16) 19(13)| 4 / \mathrm{hl}-\mathrm{I} 2 \mathrm{H}$ \\
\hline Ind & Indeno $[1,2,3-c d] p y r e n e$ & 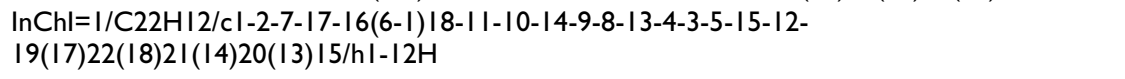 \\
\hline $\mathrm{PAH}$ & & Polycyclic Aromatic Hydrocarbon \\
\hline PDMS & & PolyDiMethylSiloxane \\
\hline $\mathrm{MeOH}$ & & Methanol \\
\hline aq & & Water \\
\hline free & & Water \\
\hline \multirow[t]{2}{*}{$\mathrm{P}$} & & Polymer \\
\hline & & Unit \\
\hline SPME & Solid Phase Micro-Extraction & \\
\hline ESD & Eqilibrium Sampling Device & \\
\hline $\mathrm{A} / \mathrm{V}$ & (surface)Area to Volume ratio & $m^{-1}$ \\
\hline LoQ & Limit of Quantification & \\
\hline QA/QC & Quality Assurance/Quality Control & \\
\hline PTFE & PolyTetraFluoroEthylene & \\
\hline$a$ & Chemical (thermodynamic) activity & \\
\hline$\gamma_{i}$ & Activity coefficient in phase i & $M^{-1}$ \\
\hline$K_{\mathrm{i} / \mathrm{j}}$ & Partition ratio between phases $\mathrm{i}$ and $\mathrm{j}$ & $\mathrm{L} / \mathrm{L}$ \\
\hline$C_{i}$ & Concentration in (phase) $i$ & $M$ \\
\hline$T$ & Thermodynamic temperature & $\mathrm{K}$ \\
\hline $\mathrm{T}_{\mathrm{m}}$ & Melting point temperature & $\mathrm{K}$ \\
\hline$V_{i}$ & Volume of phase $\mathrm{i}$ & $\mathrm{L}$ \\
\hline $\mathrm{n}_{\mathrm{a}}$ & Amount of analyte & $\mathrm{mol}$ \\
\hline$S_{(s) i}^{d}$ & Solubility (solid) in phase i & $M$ \\
\hline$n$ & number of replicate determinations & \\
\hline$r^{2}$ & Goodness of fit & \\
\hline
\end{tabular}

The bioremediation of the soil had removed a fraction of the PAHs; whereas those associated with the black carbon [40] likely remained. The residual total concentration of the 16 EPA PAHs was $120 \mathrm{mg} / \mathrm{kg}_{\text {soil }}$. This test material was selected on account of the PAH-containing soot that is claimed to complicate equilibrium sampling [25]. Prior to sampling, the soil was sieved to $2 \mathrm{~mm}$ (steel mesh) and manually homogenized.

\section{QA/QC and statistical treatment}

The qualification criteria for PAHs extracted from the ESDs included retention times within 5\% of a known sample and correct fluorescence emission wavelength(s). Signal integration was performed with HP Chemstation software (A.06.03, Agilent Tech.) and corrected by hand as necessary. About 7\% standards and solvent blanks were included in the analytical sample sequences. ESD blanks were considered unnecessary since positive blank values would be eliminated during the equilibration. The measured results were tested by least squares linear regression of $\mathrm{n}_{\mathrm{PAH}}$ on $\mathrm{V}_{\mathrm{PDMS}}$, forced through the origin. An $\mathrm{r}^{2}>0.90$ goodness of fit, was set as a necessary but not sufficient equilibrium sampling criterion. One outlier in the data set for anthracene was defined as the measured value of $\mathrm{n}_{\mathrm{ANT}}$ differed by a factor $>2$ from the predicted $(n=9)$. Equilibrium concentrations in PDMS $\left(C_{\mathrm{PDMS}}\right.$, Table 1$)$ were calculated as the arithmetic mean of the measurements $(n=$ $9-8)$. 


\section{Activity coefficients in PDMS}

For each PAH in Table 3, the activity coefficient in the Silastic ${ }^{\circledast}$ PDMS $\left(\gamma_{\text {PDMS }}\right)$ that coated the vials was determined from partitioning and solubility data:

$$
\gamma_{\mathrm{PDMS}}=\frac{a_{\mathrm{xstal}}}{\mathrm{S}_{(\mathrm{s}) \mathrm{MeOH}} K_{\mathrm{PDMS} / \mathrm{MeOH}}},
$$

where $a_{\mathrm{xstal}}$ is the activity of the PAH in its crystal state, $\mathrm{S}_{(\mathrm{s}) \mathrm{MeOH}}$ the solubility in methanol and $K_{\mathrm{PDMS} / \mathrm{MeOH}}$ is the Silastic $^{\circledast}$ PDMS-methanol partition ratio.

\section{Crystal activities}

The PAHs' activities in their pure solid crystals, also known as fugacity ratios $[41]$, at $25^{\circ} \mathrm{C}(\mathrm{T}=298 \mathrm{~K})$ were estimated from melting point temperatures $\left(\mathrm{T}_{\mathrm{m}}, \mathrm{K}\right)$, assuming their entropy of melting to be $56 \mathrm{Jmole}^{-1} \mathrm{~K}^{-1}$ (i.e. Walden's rule) as suggested by Yalkowsky et al. [42]:

$$
a_{\mathrm{xstal}}=\exp \left(6.8\left[1-\frac{\mathrm{T}_{\mathrm{m}}}{\mathrm{T}}\right]\right)
$$

\section{List of abbreviations}

See table 4.

\section{Authors' contributions}

FR carried out ESD preparation, sampling and analysis structured and wrote the manuscript. FS developed ESD preparation method and measured $K_{\mathrm{PDMS} / \mathrm{MeOH}}$. J participated in the design of the study. PM conceived the idea, shared in its design and evaluation; structured and wrote the manuscript. All authors read and approved the final manuscript.

\section{Additional material}

\section{Additional File 1}

Graph comparing published values of $S_{(s) \mathrm{MeOH}}$ for a number of PAHs; an

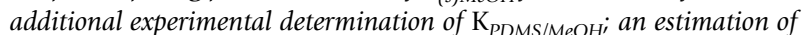
PAH's activities in urban air.

Click here for file

[http://www.biomedcentral.com/content/supplementary/1752153X-2-8-S1.doc]

\section{Acknowledgements}

Ellen Christensen (NERI, DK) measured the soil concentrations and Margit Fernquist (NERI, DK)measured solubilities. This research was funded by the Danish Technical Research Council (Young Research Leader grant), the Danish Research School of Environmental Chemistry and Ecotoxicology and the European Commission within the FP 6 Integrated Project "Novel Methods for Integrated Risk Assessment of Cumulative Stressors in the Environment" (NOMIRACLE, GOCE-003956).

\section{References}

I. Lewis GN: Outlines of a new system of thermodynamic chemistry. Proceedings of the American Academy of Arts and Sciences 1907, 43:259-293.

2. Lewis GN: The osmotic pressure of concentrated solutions, and the laws of the perfect solution. Journal of the American Chemical Society 1908, 30:668-683.

3. Sato M, Wright TL: Oxygen Fugacities Directly Measured in Magmatic Gases. Science 1966, I53:1 I03-I I05.

4. Radhakrishnan A, Anderson TG, McConnell HM: Condensed complexes, rafts, and the chemical activity of cholesterol in membranes. Proceedings of the National Academy of Sciences of the United States of America 2000, 97: 12422-I 2427.

5. Lee PH, Cheng DCH, Takayama K, Higuchi WI: Silicone Polymer Uptake Method for Determination of Cholesterol Thermodynamic Activity in Model Bile Systems. Journal of Pharmaceutical Sciences 1988, 77:610-6|4.

6. Reichenberg F, Mayer P: Two complementary sides of bioavailability: accessibility and chemical activity of organic contaminants in sediments and soils. Environmental Toxicology and Chemistry 2006, 25: 1239-1245.

7. Ditoro DM, Zarba CS, Hansen DJ, Berry WJ, Swartz RC, Cowan CE, Pavlou SP, Allen HE, Thomas NA, Paquin PR: Technical Basis for Establishing Sediment Quality Criteria for Nonionic Organic-Chemicals Using Equilibrium Partitioning. Environmental Toxicology and Chemistry 1991, 10:154I-I583.

8. Karickhoff SW: Semiempirical Estimation of Sorption of Hydrophobic Pollutants on Natural Sediments and Soils. Chemosphere 198I, 10:833-846.

9. Mackay D, Paterson S: Calculating fugacity. Environmental Science \& Technology 1981, 15:1006-1014.

10. Ferguson J: The use of chemical potentials as indices of toxicity. Proceedings of the Royal Society of London, Series B: Biological Sciences 1939, 127:387-404

II. Legind CN, Karlson U, Burken JG, Reichenberg F, Mayer P: Determining chemical activity of (semi)volatile compounds by headspace solid-phase microextraction. Analytical Chemistry 2007, 79:2869-2876.

12. Ossiander L, Reichenberg F, McLachlan MS, Mayer P: Immersed Solid Phase Micro Extraction to measure chemical activity of lipophilic organic contaminants in fatty tissue samples. Chemosphere 2008, $71: 1502-1510$

13. Yin CQ, Hassett JP: Gas-Partitioning Approach for Laboratory and Field Studies of Mirex Fugacity in Water. Environmenta Science \& Technology 1986, 20:1213-1217.

14. Wilcockson JB, Gobas FAPC: Thin-film solid-phase extraction to measure fugacities of organic chemicals with low volatility in biological samples. Environmental Science \& Technology 2001, 35:|425-|43|.

15. Golding CJ, Gobas FAPC, Birch GF: Characterization of polycyclic aromatic hydrocarbon bioavailability in estuarine sediments using thin-film extraction. Environmental Toxicology and Chemistry 2007, 26:829-836.

16. Arthur CL, Pawliszyn J: Solid-phase microextraction with thermal-desorption using fused-silica optical fibers. Analytical Chemistry 1990, 62:2145-2148.

17. Mayer P, Tolls J, Hermens JLM, Mackay D: Equilibrium sampling devices. Environmental Science \& Technology 2003, 37:I84A-I9|A [http://pubs.acs.org/cgi-bin/article.cgi/esthag-a/0000/37/i09/pdf/ 503mayer.pdf].

18. Vaes WHJ, Ramos EU, Verhaar HJM, Seinen W, Hermens JLM: Measurement of the free concentration using solid-phase microextraction: Binding to protein. Analytical Chemistry 1996, 68:4463-4467.

19. Mayer P, Vaes WHJ, Hermens JLM: Absorption of hydrophobic compounds into the poly(dimethylsiloxane) coating of solidphase microextraction fibers: High partition coefficients and fluorescence microscopy images. Analytical Chemistry 2000, 72:459-464.

20. ter Laak TL, Barendregt A, Hermens JLM: Grinding and sieving soil affects the availability of organic contaminants: A kinetic analysis. Chemosphere 2007, 69:613-620.

21. Bartkow ME, Hawker DW, Kennedy KE, Muller JF: Characterizing uptake kinetics of PAHs from the air using polyethylenebased passive air samplers of multiple surface area-to-volume ratios. Environmental Science \& Technology 2004, 38:270I-2706. 
22. Mayer P, Vaes WHJ, Wijnker F, Legierse K, Kraaij RH, Tolls J, Hermens JLM: Sensing dissolved sediment porewater concentrations of persistent and bioaccumulative pollutants using disposable solid-phase microextraction fibers. Environmental Science \& Technology 2000, 34:5I77-5I83.

23. Booij K, Hoedemaker JR, Bakker JF: Dissolved PCBs, PAHs, and HCB in pore waters and overlying waters of contaminated harbor sediments. Environmental Science \& Technology 2003, 37:42। 3-4220.

24. Lohmann R, Burgess RM, Cantwell GM, Ryba SA, MacFarlane JK, Gschwend PM: Dependency of polychlorinated biphenyl and polycyclic aromatic hydrocarbon bioaccumulation in mya arenaria on both water column and sediment bed chemical activities. Environmental Toxicology and Chemistry 2004 23:255I-256|

25. Jonker MTO, Koelmans AA: Polyoxymethylene solid phase extraction as a partitioning method for hydrophobic organic chemicals in sediment and soot. Environmental Science \& Technology 200I, 35:3742-3748.

26. Liu JF, Jonsson JA, Mayer P: Equilibrium sampling through membranes of freely dissolved chlorophenols in water samples with hollow fiber supported liquid membrane. Analytical Chemistry 2005, 77:4800-4809.

27. Minhas JK, Vasiluk L, Pinto LJ, Gobas F, Moore MM: Mobilization of chrysene from soil in a model digestive system. Environmental Toxicology and Chemistry 2006, 25: I729-I737.

28. Rusina TP, Smedes F, Klanova J, Booij K, Holoubek I: Polymer selection for passive sampling: A comparison of critical properties. Chemosphere 2007, 68: |344-135|.

29. Trimble TA, You J, Lydy MJ: Bioavailability of PCBs from fieldcollected sediments: Application of Tenax extraction and matrix-SPME techniques. Chemosphere 2008, 7 I:337-344.

30. van der Wal L, Jager T, Fleuren RHLJ, Barendregt A, Sinnige TL, Van Gestel CAM, Hermens JLM: Solid-phase microextraction to predict bioavailability and accumulation of organic micropollutants in terrestrial organisms after exposure to a fieldcontaminated soil. Environmental Science \& Technology 2004 38:4842-4848.

31. Ter Laak TL, Agbo SO, Barendregt A, Hermens JLM: Freely dissolved concentrations of PAHs in soil pore water: Measurements via solid-phase extraction and consequences for soil tests. Environmental Science \& Technology 2006, 40:1307-13 I3.

32. Petersen DG, Reichenberg F, Dahllof I: Phototoxicity of pyrene affects benthic algae and bacteria from the Arctic. Environmental Science \& Technology 2008, 42:137|-1376.

33. Allen JO, Sarofim AF, Smith KA: Thermodynamic properties of polycyclic aromatic hydrocarbons in the subcooled liquid state. Polycyclic Aromatic Compounds 1999, I3:26I-283.

34. Van Noort PCM: Fugacity ratio estimations for high-melting rigid aromatic compounds. Chemosphere 2004, 56:7-12.

35. Boyd BJ, Porter $\mathrm{CJ} H$, Charman WN: Using the polymer partitioning method to probe the thermodynamic activity of poorly water-soluble drugs solubilized in model lipid digestion products. Journal of Pharmaceutical Sciences 2003, 92: | 262-I 27| .

36. Cornelissen G, Pettersen A, Broman D, Mayer P, Breedveld GD: Field Testing of Equilibrium Passive Samplers to Determine Freely Dissolved Native Polycyclic Aromatic Hydrocarbon Concentrations. Environmental Toxicology and Chemistry 2008, 27:499-508.

37. Booij K, Smedes F, van Weerlee EM: Spiking of performance reference compounds in low density polyethylene and silicone passive water samplers. Chemosphere 2002, 46: I| $57-1|6|$.

38. Miljøstyrelsen: Jordforureningsloven. [http://www.mst.dk//ord/ lordforureningsloven/].

39. Tsapakis M, Stephanou EG: Occurrence of gaseous and particulate polycyclic aromatic hydrocarbons in the urban atmosphere: study of sources and ambient temperature effect on the gas/particle concentration and distribution. Environmental Pollution 2005, 133:147-156.

40. Cornelissen G, Gustafsson O, Bucheli TD, Jonker MTO, Koelmans AA, Van Noort PCM: Extensive sorption of organic compounds to black carbon, coal, and kerogen in sediments and soils: Mechanisms and consequences for distribution, bioaccumulation, and biodegradation. Environmental Science \& Technology 2005, 39:688I-6895.
4I. Mackay D, Shiu WY, Ma KC: Illustrated handbook of physicalchemical properties and environmental fate for organic chemicals. Volume II: polynuclear aromatic hydrocarbons, polychlorinated dioxins and dibenzofurans. In Illustrated handbook of physical-chemical properties and environmental fate for organic chemicals Boca Raton, FL, Lewis Publishers; 1992.

42. Yalkowsky SH, Orr RJ, Valvani SC: Solubility and partitioning. 3. The solubility of halobenzenes in water. Industrial \& Engineering Chemistry Fundamentals 1979, I 8:351-353.

\section{Publish with ChemistryCentral and every scientist can read your work free of charge \\ "Open access provides opportunities to our \\ colleagues in other parts of the globe, by allowing anyone to view the content free of charge." \\ W. Jeffery Hurst, The Hershey Company.}

- available free of charge to the entire scientific community

- peer reviewed and published immediately upon acceptance

- cited in PubMed and archived on PubMed Central

- yours - you keep the copyright

Submit your manuscript here:

http://www.chemistrycentral.com/manuscrip



